\title{
Evaluation of ship-based electromagnetic-inductive thickness measurements of summer sea-ice in the Bellingshausen and Amundsen Seas, Antarctica
}

\author{
Christian Haas * \\ Alfred Wegener Institute, Columbusstr., D-27568 Bremerhaven, Germany \\ Received 24 December 1996; accepted 3 October 1997
}

\begin{abstract}
The accuracy of electromagnetic-inductive (EM) sea-ice thickness measurements performed from a moving icebreaker is evaluated. Ice thickness distributions and ridge statistics are derived. In the Bellingshausen Sea the ice was moderately deformed with mean and modal ice thicknesses of 1.3 and $0.9 \mathrm{~m}$, respectively. In contrast, the heavily deformed ice in the Amundsen Sea had mean thicknesses between 2.3 and $3.1 \mathrm{~m}$, with modes between 1.6 and 2.7 m. By means of the measured apparent electrical conductivity on ice of known thickness, the conductivity of the perennial summer ice was found to be significant and could not be neglected in the calibration of EM measurements. The high conductivity is mainly due to the widespread occurrence of seawater-filled gaps close to the ice surface. The system, consisting of commercially available instruments, yielded reliable mean thickness estimates. This is shown by comparison with drill-hole measurements and visual observations. However, the thickness profiles appear highly low-pass filtered compared to their surface height profile determined with a laser altimeter. Thus the system possesses a limited lateral resolution such that the thickness of single pressure ridges cannot be resolved. This is only in part attributed to the trade-off between increasing instrument height and decreasing lateral resolution of EM measurements. The low resolution is mainly due to the particular EM instrument, as its sensitivity is highly reduced if used far above the water surface, and it has a comparatively long time constant of 1 s. Additionally, the water-filled gap in the ice generally reduces the sensitivity of the measured apparent conductivity to ice thickness changes. (C) 1998 Elsevier Science B.V.
\end{abstract}

Keywords: EM sea-ice thickness measurements; Drill-hole measurements; Summer sea-ice properties; Bellingshausen Sea; Amundsen Sea

\section{Introduction}

Electromagnetic-inductive (EM) sounding has increasingly been employed during recent years to determine sea-ice thickness, in addition to the use of submarine sonar and drilling surveys (e.g. Wadhams,

\footnotetext{
*E-mail: chaas@awi-bremerhaven.de; fax: +49 (471) 4831149.
}

1994; and others, see below). The method has been and is currently used in scientific sea-ice investigations, engineering tasks and for validating remote sensing data. With ground-based measurements, an EM instrument is placed directly onto the ice surface (Kovacs and Morey, 1991; Haas et al., 1997; A.P. Worby, unpubl. data). In airborne surveys, the instrument is operated either when suspended below a helicopter (Kovacs et al., 1987; Kovacs and Holla- 
day, 1990; Liu and Becker, 1990; Prinsenberg and Holladay, 1993) or when mounted in a fixed-wing airplane (Multala et al., 1995). Typically, the EM instruments are flown at heights of 20 to $30 \mathrm{~m}$ above the ice surface.

EM measurements utilize the large contrast in electrical conductivity between sea ice and seawater. The former is well known to range between 0 and 30 $\mathrm{mS} / \mathrm{m}$ in the Arctic (Morey et al., 1984; Kovacs and Morey, 1988; Haas et al., 1997), the latter varies from 2300 to $2900 \mathrm{mS} / \mathrm{m}$ (e.g. Coachman and Aagaard, 1974). Consequently the conductivity of the sea ice is negligible in comparison to the seawater conductivity. Therefore, a quasi-static lowfrequency EM field generated by the transmitter coil of an EM instrument will induce eddy currents mainly in the seawater below the ice. This, in turn, will result in a secondary field which is sensed by a receiver coil. The secondary-to-primary field ratio can be expressed in terms of an apparent conductivity $\sigma_{\mathrm{a}}$, a measure of the integrated electrical conductivity of the halfspace underneath the instrument. If ice and water conductivities are considered to be constant, $\sigma_{\mathrm{a}}$ is only dependent on the instruments height above the sea surface, which is identical with the sea-ice underside. Ice thickness can then be calculated if the height of the instrument above the ice surface is known (e.g. Kovacs et al., 1987). With airborne systems, the latter is determined by means of a laser altimeter which simultaneously profiles the range to the ice surface.

Over deformed ice, in particular pressure ridges, the accuracy of electromagnetically derived ice thickness can be very poor if results are compared with drill-hole determined values on a point-to-point basis. While mean values for full ridge cross-profiles agree reasonably well, maximum keel depths are generally underestimated (Kovacs and Holladay, 1990; Haas et al., 1997). This is mainly due to the extended area over which eddy currents are induced in the water below the instrument (the 'footprint'). Kovacs et al. (1995) estimate the footprint size for different coil configurations to range between 1.3 and 3.8 times the instrument height above the water surface. Consequently, the lateral resolution of EM measurements decreases with increasing instrument height, which is a major problem in airborne surveys.
Regarding the vertical resolution, another problem arises with airborne systems due to the negative-exponential relationship between $\sigma_{\mathrm{a}}$ and the height $h$ above the water surface (see below and Figs. 6 and 8). This implies that the gradient $\mathrm{d} \sigma_{\mathrm{a}} / \mathrm{d} h$ decreases with increasing instrument height. Thus, to resolve $\sigma_{\mathrm{a}}$ changes due to varying ice thicknesses at greater instrument heights, the use of sophisticated instruments with a high sensitivity to changes in $\sigma_{\mathrm{a}}$ is required.

In this paper, the potential of continuous measurements from an icebreaker with a low-cost, commercially available EM instrument is investigated. The same instrument is frequently used for point measurements of ice thickness, when it is placed directly on the ice surface. Here, the device was suspended below the bow crane of the German research vessel Polarstern, close to the water surface and used in combination with a laser altimeter. In principle, the close proximity to the ice provides good lateral and vertical resolution. In addition, the ice-breaking vessel allowed for good progress along extended profiles. Thus, this kind of measurements may provide a valuable link between ground-based and airborne surveys.

While the paper is mainly aimed to describe and evaluate the properties of the system, we also display the derived thickness distributions. Further, results from accompanying ground-based EM and drill-hole measurements as well as from ice core analyses are presented. These were carried out to calibrate and validate the ship-based EM results. In turn, from the ground-based EM data ice properties are derived.

The measurements were performed as part of a geophysical expedition to the Bellingshausen and Amundsen Seas, Antarctica, during February 1994 (Fig. 1). This region has a perennial sea-ice cover where only few ice thickness measurements have been performed so far (Jeffries et al., 1994; Worby et al., 1996). Thus, we present the first extensive thickness data set for the perennial ice of this region. This is discussed in Appendix A.

\subsection{Definition of some important sea-ice parameters}

As EM measurements cannot distinguish between snow and ice, here ice thickness $z_{\mathrm{i}}$ always means the total ice plus snow thickness, and snow and ice 


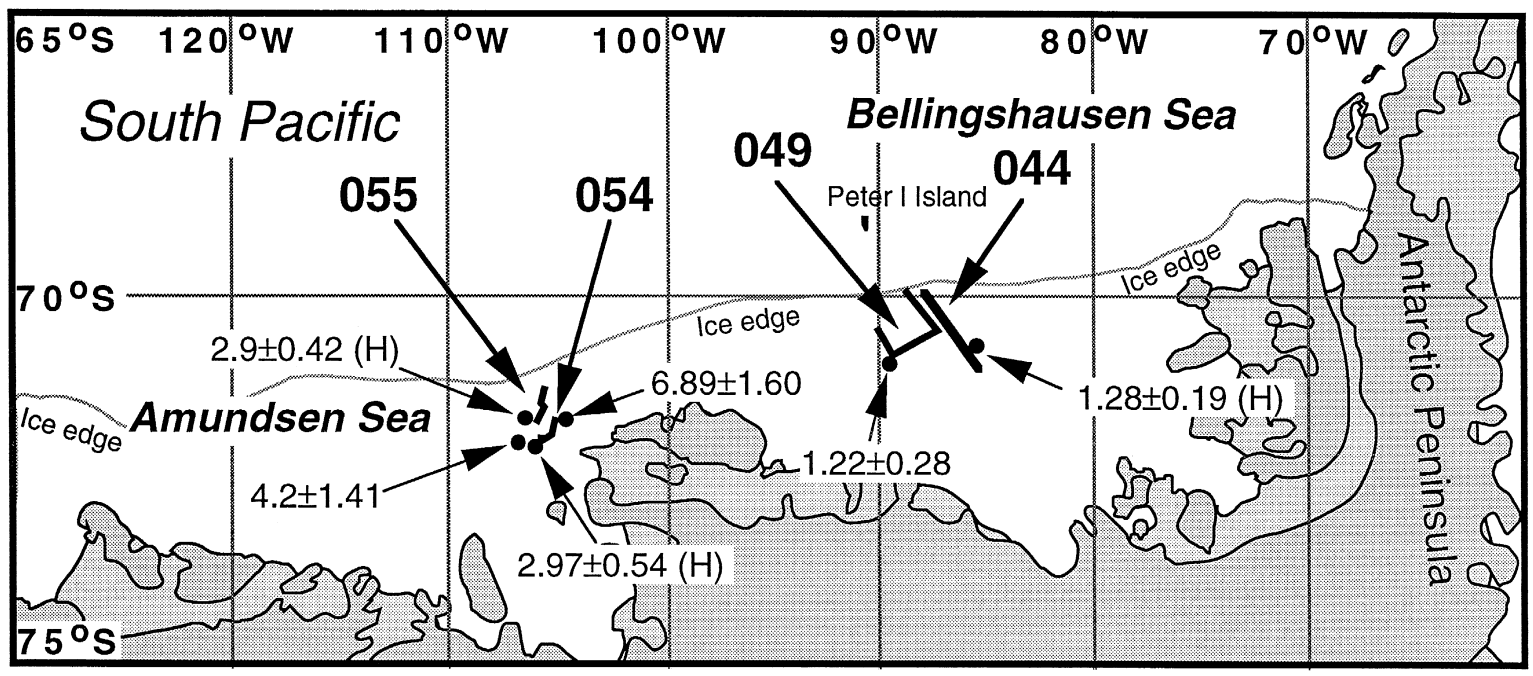

Fig. 1. Map of the expedition region in the Bellingshausen and Amundsen Seas showing the locations of the four thickness profiles (044, 049, 054, 055) measured from the ship (thick lines). The heavy dots indicate locations of drill-hole measurements either along a short profile on a single floe or at stops during a helicopter flight to several floes (marked with $(H)$; see text). For each location, mean ice thickness and its standard deviation is given in $\mathrm{m}$.

surface are used synonymously. Apart from $z_{\mathrm{i}}$ and snow thickness, freeboard and draft are important variables to characterise the surface and bottom profiles of ice floes. Freeboard is the height of the floe surface above the water level, and draft is the depth of the ice underside below that datum (Fig. 2). Of particular interest are the draft and freeboard of pressure ridges as they contain much of the total ice volume and are a serious obstacle for shipping.
Pressure ridges are formed by ice deformation in converging ice fields. The top and bottom parts of a pressure ridge are called ridge sail and keel, respectively (Fig. 2). However, it should be noted here that ice deformation will not always results in the formation of a real pressure ridge, as would be defined, e.g. by a Rayleigh criterium (e.g. Wadhams and Davy, 1986). Instead, due to rafting deformed ice can also be composed of accumulations of ice blocks

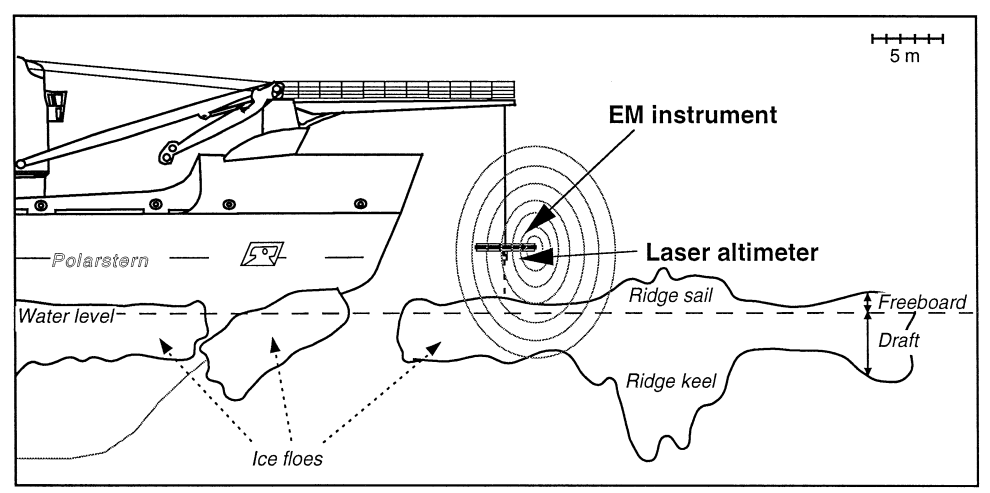

Fig. 2. Scaled sketch showing the system configuration of the ship-based measurements at the bow of RV Polarstern profiling an ice floe with a pressure ridge. Definitions of freeboard and draft are also given. 
underneath a virtually intact ice floe such that it lacks a clearly identifiable ridge sail. This has frequently been observed by Worby et al. (1996), Haas et al. (1996) and Jeffries et al. (1997), particularly in the Bellingshausen and Amundsen Seas.

\section{Measurements and methods}

Visual observations of general ice conditions were performed hourly to two-hourly from the bridge of RV Polarstern and are reported by Haas and Viehoff (1994). The sea-ice programme consisted of thickness and ice core drilling as well as ground- and ship-based EM measurements (Haas et al., 1996). The latter were performed along four profiles with a total length of $235 \mathrm{~km}$ (profiles 044, 049, 054 and 055 in Fig. 1). Profile numbers correspond to the Julian Days of the surveys.

All EM measurements were carried out with a Geonics EM31, which was also used by Kovacs and Morey (1991) and Haas et al. (1997). This is a portable, small-offset loop-loop steady-state induction device which is commercially available and frequently used to solve shallow engineering geophysical problems. The spacing between the coplanar transmitter and receiver antenna coils is $3.66 \mathrm{~m}$, and the operating frequency is $9.8 \mathrm{kHz}$. The instrument can be operated with either vertically or horizontally aligned coils, corresponding to the horizontal or vertical magnetic dipole (HDM or VDM) mode, respectively. The subsurface apparent conductivity $\sigma_{\mathrm{a}}$ is directly indicated in $\mathrm{mS} / \mathrm{m}$. A time constant of $1 \mathrm{~s}$ is specified by the manufacturer, which can strongly limit measurements with a moving instrument.

\subsection{Ground-based measurements}

Nine 20 to $100 \mathrm{~m}$ long thickness profiles with hole spacings of $4 \mathrm{~m}$ were drilled on virtually level sections of single floes. In addition, during six helicopter flights, five to ten different floes in a wider area around the ship were visited and a single thickness was measured in a drill hole at a representative spot on each floe. This provided a better overview of the regional thickness variability. At 80 of these drill-hole locations $\sigma_{\mathrm{a}}$ was determined with the EM instrument positioned directly on the ice or snow surface and operated in HMD mode (cf. Kovacs and Morey, 1991; Haas et al., 1997). With these measurements, the validity of the $\sigma_{\mathrm{a}} / z_{\mathrm{i}}$ calibration established for Arctic sea ice was verified.

To calculate the electrical conductivity of the ice, temperature and salinity were measured on 30 ice cores from 15 floes (Morey et al., 1984; Haas et al., 1997). In most cases, these floes were the same ones where thickness profiles were also drilled.

\subsection{Ship-based measurements}

Fig. 3 gives a definition of the parameters measured from the ship as described below. The shipbased EM measurements were performed in the VMD mode to achieve a better depth penetration and thus a higher resolution of thicker ice than would be possible in HMD mode (Kovacs et al., 1995). After calibration, the EM instrument yields the system distance to the water surface $d_{\mathrm{EM}}$ (Fig. 3). The vertical height of the instrument above the ice surface $d_{\text {Laser }}$ was determined with a downward looking laser distance meter. The laser was a PS100E (IBEO, Hamburg), operating at a wavelength of $905 \mathrm{~nm}$ and a nominal accuracy of $\pm 0.03 \mathrm{~m}$. It has a ray divergence of $0.24^{\circ}$, resulting in a footprint diameter of a few $\mathrm{cm}$, depending on instrument height. Apart from $d_{\text {Laser }}$, the laser yields received signal return amplitude in relative units, which can be used to distinguish between ice and water.

The EM instrument was fixed in a wooden frame to enable suspension below the bow crane and for

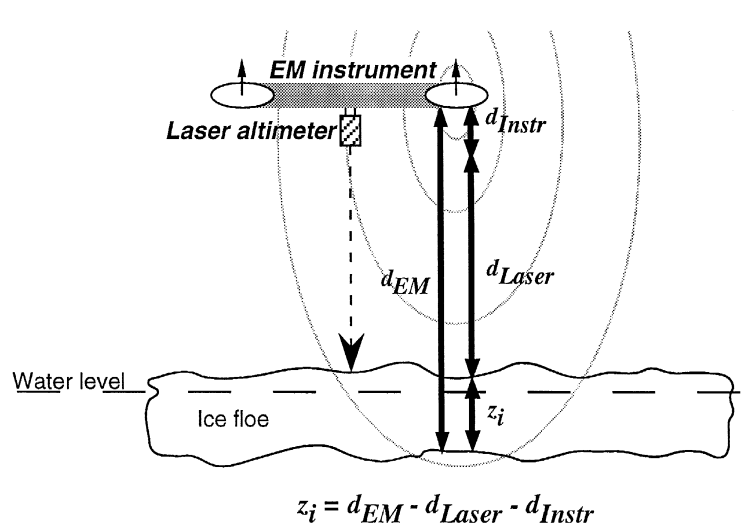

Fig. 3. Sketch showing the calculation of ice thickness $z_{\mathrm{i}}$ from $\mathrm{EM}$ and laser-determined distances $d_{\mathrm{EM}}$ and $d_{\mathrm{Laser}}$. 
mechanical protection. A heated box with the laser was also mounted on the frame (Fig. 2). The total weight of the EM/laser system was about $50 \mathrm{~kg}$. The system was suspended by means of the crane's hook with the axis between the coils being perpendicular to the ship's axis. The system height above the water surface was approximately $4 \mathrm{~m}$. At this height, the shortest distance to the bow was $8 \mathrm{~m}$, and the distance to the intersection of bow and water surface $15 \mathrm{~m}$ (Fig. 2). To avoid swaying in the steaming direction, the system was also fixed with two slightly tightened ropes to each side of the bow. This also effectively reduced oscillations normal to the steaming direction to $1-2 \mathrm{~m}$ even if the ship moved heavily when breaking thick ice.

Data acquisition was achieved with a personal computer equipped with the laser control board and a 12-bit A/D converter for the EM31 apparent conductivity analog output. To achieve a satisfactory resolution, the EM signal had to be preamplified 25 times. Data were sampled with frequencies of 20 or $50 \mathrm{~Hz}$ depending on ship speed. With speeds between 2 and $4 \mathrm{~m} / \mathrm{s}$ this resulted in point spacings from 0.08 to $0.1 \mathrm{~m}$. Accurate navigational data were read from the ship's information system.

A calibration measurement was performed to check the influence of the ship and other electrically conducting objects. For this, the EM/laser system was elevated above and lowered down to the water surface with the bow crane when the ship was stationary in open water and no ice was underneath the instruments. In this case, $d_{\mathrm{EM}}$ and $d_{\text {Laser }}$ are equal. Therefore, the relationship between $\sigma_{\mathrm{a}}$ and $d_{\mathrm{EM}}$ could be measured and compared with theoretical curves.

\subsection{EM modelling}

To explain the measured relation between $\sigma_{\mathrm{a}}$ and $z_{\mathrm{i}}$ gathered from the ground-based soundings and to obtain a $\sigma_{\mathrm{a}}$-to- $d_{\mathrm{EM}}$ transformation for the bow measurements, one-dimensional forward modelling of the EM response to a layered subsurface representing the ice and the water underneath was performed. Full solution formulas as given, e.g. by Ward and Hohmann (1988) and a digital filter method (Anderson, 1979) were used.

\subsection{Analysis of ship-based data}

The main aim of this paper is to evaluate the potential of the EM/laser system as is expressed by the accuracy and the lateral resolution of ice thicknesses. While the former can only be validated by comparison with drill-hole data, the latter is analysed by several means. Frequency analysis of the EM and laser data are performed to obtain their frequency content as a measure of their potential for resolving rapid spatial thickness variations, for example at pressure ridges or floe edges. Therefore, calculations of power spectral densities

$\operatorname{PSD}(f)=\frac{1}{N^{2}}|G(f)|^{2}$

with $G(f)$ being the Fourier transform of the measured time series $y(t)$, e.g. $y(t)=z_{\mathrm{i}}(t)$, consisting of $N$ samples, and of normalized autocorrelation functions

$$
\begin{aligned}
\operatorname{ACF}(\tau)= & \frac{1}{N-1} \sum_{i=1}^{N}\left(y\left(t_{i}\right)-\bar{y}\right) \\
& \times\left(y\left(t_{i}+\tau\right)-\bar{y}\right) / s^{2}
\end{aligned}
$$

with $s^{2}$ being the variance of $y(t)$ have been performed. The PSD gives the power of a signal at a certain frequency $f$. Similarly, the rapidity of the tail-off of the ACF is a measure of the variability contained in the data (e.g. Rothrock, 1986). The slower it tails off, the smoother and less variable is the considered time series. The correlation length or the lag $\tau$ for which $\operatorname{ACF}(\tau)=1 / \mathrm{e} \operatorname{ACF}(0)$ is considered a typical length scale in the data. Measurements at points with a spacing of more than the correlation length are considered to be statistically independent. If the high-resolution laser data are believed to contain the full surface roughness information, in particular the high-amplitude variations like pressure ridges and floe edges, then comparison of these data with the EM data reveals the degree of smoothing and loss of lateral resolution.

Finally, we look at probability density functions

$\operatorname{PDF}(z)=\operatorname{Prob}(z<z(x)<z+\mathrm{d} z) / \mathrm{d} z$ 
with $z(x)$ a given variable at a distance $x$ along the profile. The PDF specifies the probability that $z(x)$ lies between $z$ and $z+\mathrm{d} z$, where $\mathrm{d} z$ is the bin width of the distribution. Here, PDFs of the variables $z_{\mathrm{i}}$, freeboard and draft are considered.

During Arctic traverses the tails of freeboard and draft PDFs were shown to be very similar if a simple transformation was applied to the freeboard PDF (Comiso et al., 1991; Wadhams et al., 1992). The transformation is based on $R$, the ratio of mean draft and freeboard. It is performed by multiplying the abscissa (the freeboard axis) and dividing the ordinate (the PDF axis) of the freeboard PDF by $R$. The good agreement between the tails of the PDFs generally means that-statistically-for all height intervals of pressure ridge sails there are corresponding numbers of keels as well. In the present study, freeboard is solely measured by the laser, while draft is determined solely by the EM instrument. By comparing the freeboard and draft PDFs we can therefore check whether the EM instrument is able to measure the full range of keel depths or not, assuming that observations from the Arctic are also valid for the Bellingshausen and Amundsen Seas.

\section{Data processing}

Fig. 4 gives an example of a raw data record of 300 s. Over ice, the laser receives strong signal returns while over water there are many data gaps (Fig. 4a,b). By means of the signal return amplitude and the few data from the water surface, the water surface is reconstructed and ice concentration as well
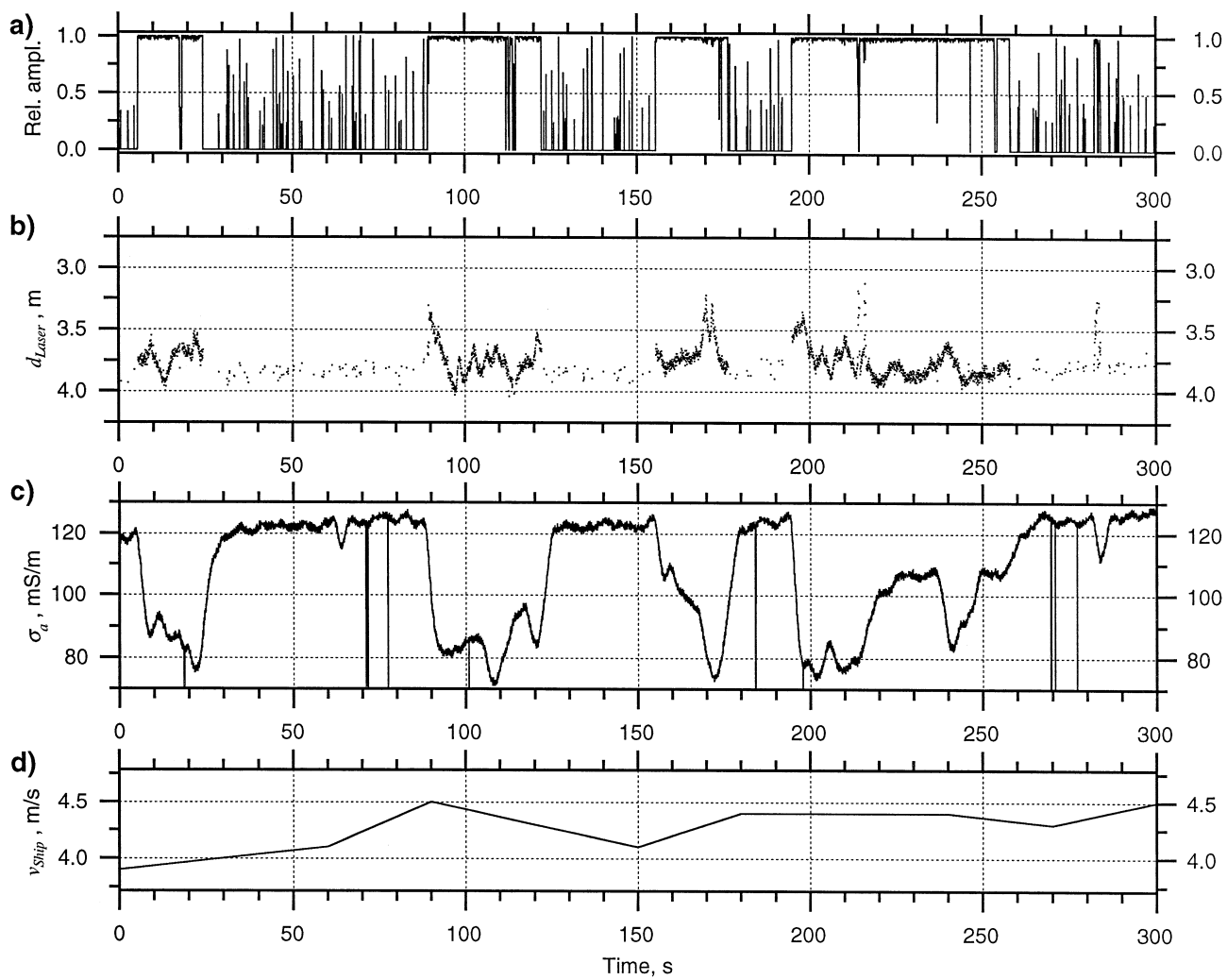

Fig. 4. $300 \mathrm{~s}$ long section of raw data from the Bellingshausen Sea gathered from the ship's bow. (a) Relative laser signal return amplitude. (b) System distance to the ice or water surface $d_{\text {Laser }}$ measured by the laser. (c) Electromagnetically determined apparent subsurface conductivity $\sigma_{\mathrm{a}}$. (d) Ship's speed $v_{\text {ship }}$. 
as floe size distributions can be calculated. As the laser measurements are comparable to those from helicopters or aircrafts the ship motion (pitch) inherent in the data can be removed. This was achieved by means of a three-step filtering method described by Hibler (1972) which yields the surface of flat ice as a reference level. Subsequently, ridge statistics can be derived (see Section 4.3.4).

As can be seen in Fig. 4c, as the EM instrument crosses ice floes $\sigma_{\mathrm{a}}$ strongly decreases in response to the increased distance of the water surface as compared to the ice-free case.

Fig. 4d shows the varying ship speed along the profile. As this can result in highly varying spatial sampling, the speed information was used to resample all data to an equidistant point spacing of $0.5 \mathrm{~m}$. Data acquired with ship speeds of less than $0.5 \mathrm{~m} / \mathrm{s}$ or negative values during ramming were completely eliminated.

The derivation of ice thickness is rather straightforward as indicated in the sketch in Fig. 3. The laser-determined distance $d_{\text {Laser }}$ to the water or ice surface as well as the spacing $d_{\text {Instr }}$ between laser and EM device is subtracted from the distance $d_{\mathrm{EM}}$ of the system to the water surface or ice underside. While the former two distances are indicated by the laser or measured directly, $d_{\mathrm{EM}}$ has to be derived first from a calibration formula to transform $\sigma_{\mathrm{a}}$ into $d_{\mathrm{EM}}$. Here, the presentation of this calibration is deferred to Section 4.3.1. Because vertical motions of the system due to ship motion during ice-breaking have the same amplitude and sign in $d_{\mathrm{EM}}$ and $d_{\text {Laser }}$ they are effectively eliminated by the subtraction.

Fig. 5 shows the results of the data processing. The data points now have a constant spacing of 0.5 $\mathrm{m}$ and time is converted to distance on the abscissa. The laser data are corrected for data gaps over open water (Fig. 5a) and are analysed for the distribution of ice and water (Fig. 5b). The subtraction of $d_{\text {Laser }}$ from $d_{\mathrm{EM}}$ in Fig. 5a results in the interpreted ice thickness (Fig. 5c). A first, quality check of the processing result is evident from the ice thickness determined over open water, which obviously should equal zero.

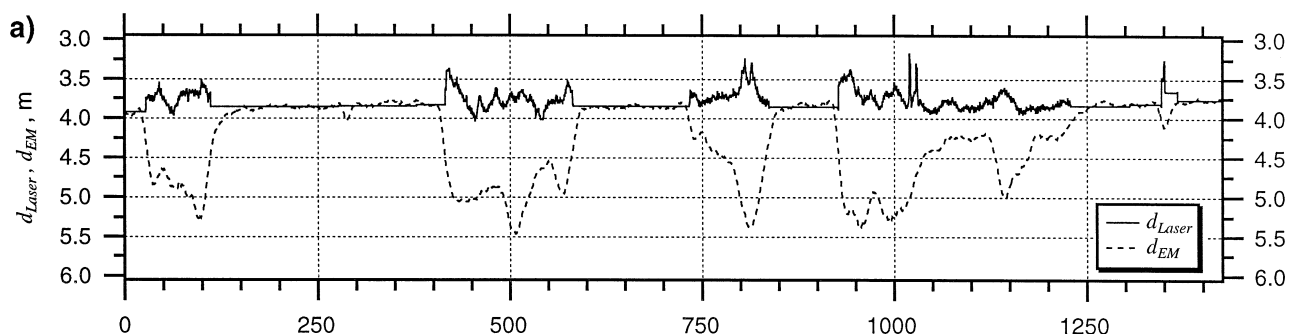

b)
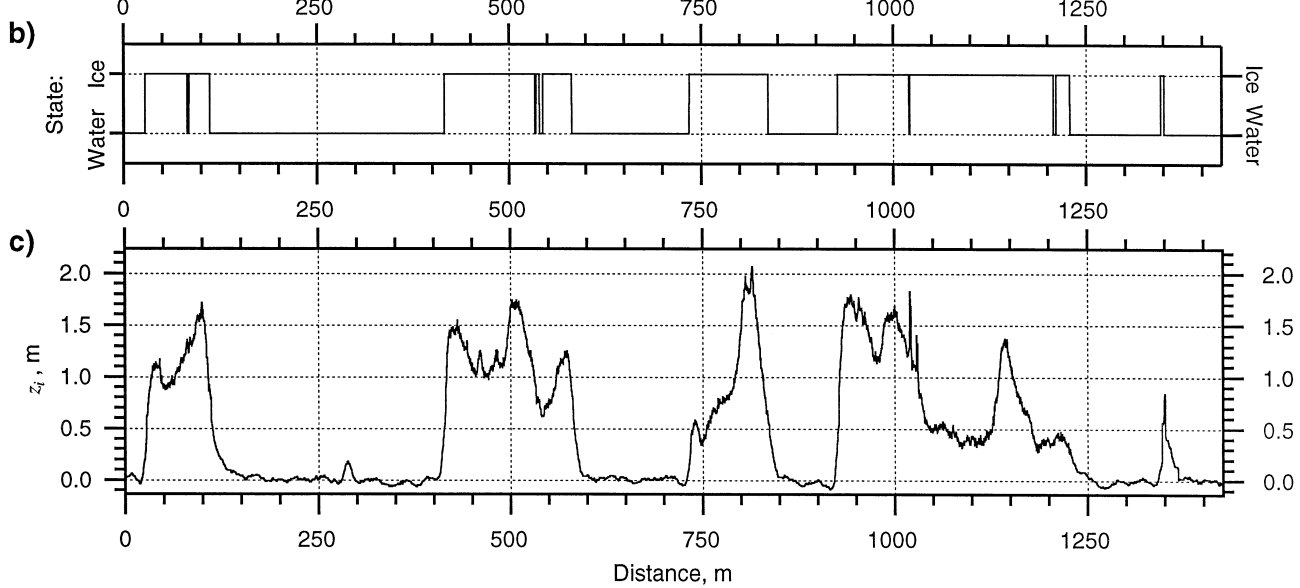

Fig. 5. Processed data from Fig. 4 (a) Distances $d_{\text {Laser }}$ and $d_{\mathrm{EM}}$ of the system to the ice surface and underside. Both distances are equal over open water. (b) Distribution of ice and water as derived from the signal return amplitude of the laser data. (c) Ice thickness $z_{\mathrm{i}}$ as the result of subtraction of $d_{\text {Laser }}$ from $d_{\mathrm{EM}}$ in (a). 


\section{Results}

\subsection{Ice conditions}

Visual estimates from the ship's bridge (Haas and Viehoff, 1994) indicated level ice thicknesses between 0.5 and $2 \mathrm{~m}$ in the central Bellingshausen Sea, with the majority of observations between 0.8 and $1.2 \mathrm{~m}$. Ice concentrations ranged between 50 and $100 \%$, with typical floe diameters ranging from 10 to several $100 \mathrm{~m}$. In the eastern Amundsen Sea thicknesses between 0.8 and $4 \mathrm{~m}$ were observed with ice concentrations greater than $90 \%$. Floe sizes also ranged between 10 and several $100 \mathrm{~m}$. In both regions, the ice was mostly covered by snow of some decimetres in thickness. It appeared to be highly rotten, often showing honeycomb-like pore clusters and highly porous layers or gaps close to the ice surface.

\subsection{Ground-based measurements}

Mean and standard deviation of ice thickness as derived by drilling are shown in Fig. 1 for each station or helicopter flight ('H') (see also Fig. 12). The mean ice thickness of all $n$ sampled floes (profile measurements and helicopter flights) in the central Bellingshausen Sea along the ship profiles 044 and 049 was $1.27 \pm 0.59 \mathrm{~m}(n=13)$. Along profiles 054 and 055 in the eastern Amundsen Sea the ice was much thicker with a mean of $3.33 \pm 1.72 \mathrm{~m}$ $(n=13)$.

Fig. 6 shows the measured relation between apparent conductivity and ice (plus snow) thickness. An exponential fit explaining $97 \%$ of the total variance is also shown (solid line). The stippled line is a two-layer model curve for ice with a conductivity of $23 \mathrm{mS} / \mathrm{m}$ over water of $2600 \mathrm{mS} / \mathrm{m}$, typical values of Arctic first- and multi-year ice in summer (Haas et al., 1997). The data presented here show much higher apparent conductivities for the respective thicknesses. The differences cannot be explained by increased ice or water conductivities alone (curves not shown here; see Haas, 1997). Instead, the increased apparent conductivity is believed to be a result of the occurrence of slush and seawater-filled gaps with extremely high porosities within the upper ice sections. These gaps were a widespread phe-

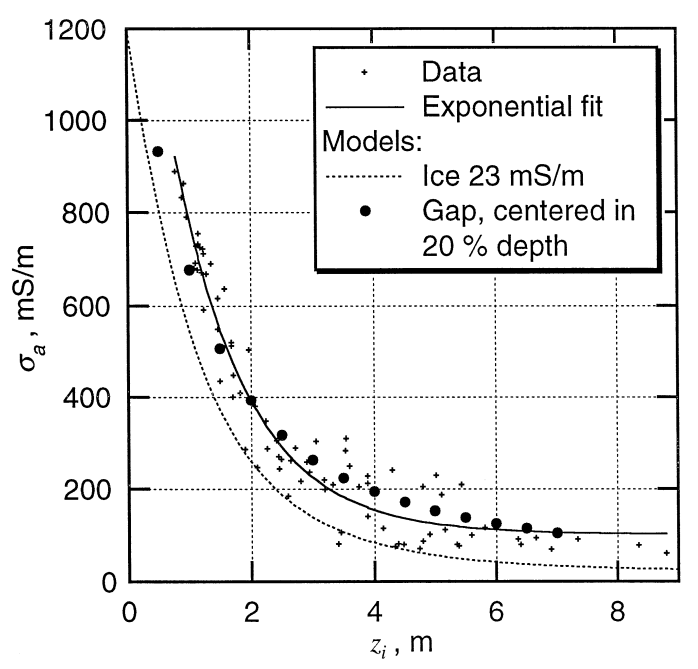

Fig. 6. Apparent conductivity $\sigma_{\mathrm{a}}$ measured in HMD mode versus ice thickness $z_{\mathrm{i}}$ derived from drilling. Data (crosses) and an exponential fit (solid line) are shown as well as model curves for ice with a conductivity of $23 \mathrm{mS} / \mathrm{m}$ (dashed) and the gap model from Fig. 7 (heavy dots) with a seawater conductivity of 2600 $\mathrm{mS} / \mathrm{m}$.

nomenon observed when floes were overturned during ice-breaking (Haas and Viehoff, 1994; Thomas et al., 1997) and appeared to be confined to the freeboard layer (Ackley and Sullivan, 1994).

Fig. 7a shows a normalized mean depth profile of ice conductivity calculated from the salinity and temperature profiles of 30 ice cores sampled at different locations. At a relative depth of 0.2 an increased conductivity and higher variability due to the reported gaps can be seen. Because the seawater and slush filling the gaps was mostly lost during core recovery the derived conductivity value for the gap is likely to be still much too low. Therefore, a four-layer model of overlying ice, a seawater-filled gap, the ice beneath and finally seawater was assumed. The thinner upper ice layer was given a conductivity of $0 \mathrm{mS} / \mathrm{m}$ to also account for the snow on top of the ice. The lower ice was assumed to have a conductivity of $60 \mathrm{mS} / \mathrm{m}$, in accordance with the values from Fig. 7a. For the gap a constant thickness of $0.15 \mathrm{~m}$ and the seawater conductivity of $2600 \mathrm{mS} / \mathrm{m}$ was taken. The model is shown in Fig. $7 \mathrm{~b}$. Here, ice thickness is defined to be the sum of the thicknesses of the two ice layers and the gap. The modelled results are included in Fig. 6 (circles) and 


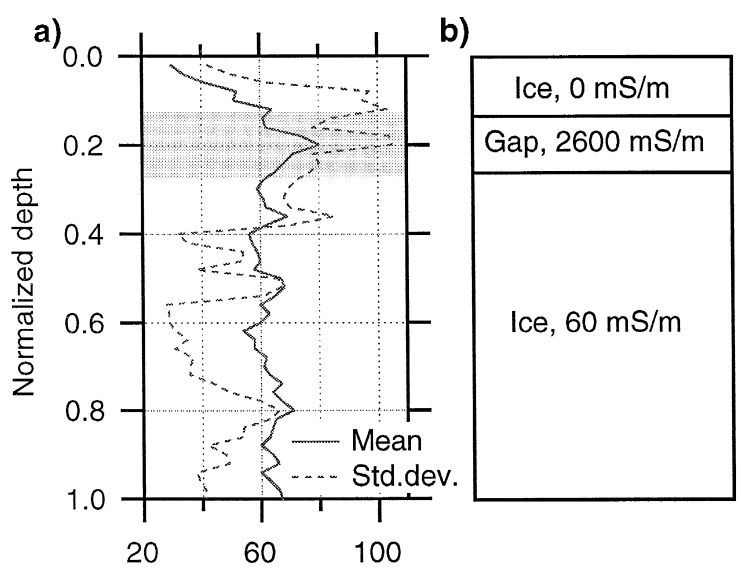

Ice conductivity, $\mathrm{mS} / \mathrm{m}$

Fig. 7. (a) Mean (solid line) and standard deviation (dash line) of ice conductivity with depth as derived from ice core analyses. (b) Layered subsurface model containing a seawater-filled gap deduced from (a). This model was used to calculate the $\sigma_{\mathrm{a}}\left(z_{\mathrm{i}}\right)$ in Fig. 6 and $\sigma_{\mathrm{a}}\left(d_{\mathrm{EM}}\right)$ in Fig. 8b.

explain the measured data and the increased apparent conductivities reasonably well.

\subsection{Ship-based measurements}

\subsection{1. $\sigma_{a}$-to- $d_{E M}$ transformation}

Fig. 8a shows the result of the calibration measurements over open water as described in Section
2.2. The negative exponential relationship between $\sigma_{\mathrm{a}}$ and $d_{\mathrm{EM}}$ is apparent. A model curve with a spacing $d_{\text {Instr }}$ of $0.22 \mathrm{~m}$ between EM instrument and laser explains the measured data very well and thus confirms the absence of disturbances by electric conductors like the crane or the ship's bow.

The ground-based measurements showed that ice conductivity was not negligible at most locations (see above). This is also important for the ship-based measurements, and has to be taken into account for the transformation of $\sigma_{\mathrm{a}}$ into $d_{\mathrm{EM}}$. Therefore, the same gap model employed to explain the measured relation between $\sigma_{\mathrm{a}}$ and $z_{\mathrm{i}}$ in Fig. 6 is used here to derive an equation for $d_{\mathrm{EM}}$ for the bow measurements. Accordingly, $\sigma_{\mathrm{a}}$ has been calculated for a constant instrument height of $4 \mathrm{~m}$ above the ice surface, the distance to the water surface being the sum of this height plus ice thickness (including the gap). The results are shown in Fig. 8b. It can be seen that $\sigma_{\mathrm{a}}$ is significantly increased compared to the case of non-conducting ice, shown for a three-layer model of air, ice and seawater (dashed line, same as in Fig. 8a). An exponential fit to the model points yields:

$d_{\mathrm{EM}}=14.3-\ln \left(\sigma_{\mathrm{a}}-22.1\right) / 0.438$

(solid line in Fig. 8b). The same apparent conductivities thus result in a bigger estimate of $d_{\mathrm{EM}}$. For example, a measured $\sigma_{\mathrm{a}}$ of $40 \mathrm{mS} / \mathrm{m}$ now yields
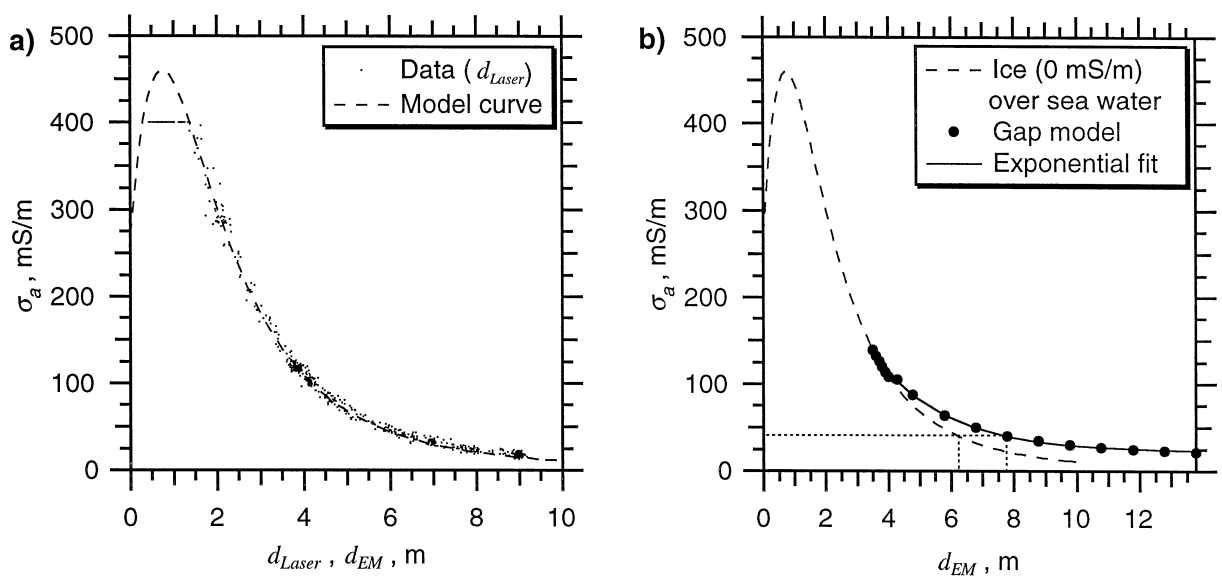

Fig. 8. (a) Apparent conductivity $\sigma_{\mathrm{a}}$ measured in VMD mode versus system height above the water surface $d_{\text {Laser }}$ during calibration measurements over open water (see text). The data are well described by a two-layer model curve of air over seawater with a conductivity of $2600 \mathrm{mS} / \mathrm{m}$. (b) The model curve from (a) (dashed) and its modification due to the introduction of conductive ice according to the gap model in Fig. 7 (dots and solid line; Eq. (1)). The stippled lines explain the different estimate of $d_{\mathrm{EM}}$ due to the different model curves. 
$d_{\mathrm{EM}}=7.7 \mathrm{~m}$ as compared to $d_{\mathrm{EM}}=6.2 \mathrm{~m}$ for the case of non-conducting ice (stippled lines in Fig. 8b). With $d_{\text {Laser }}=4 \mathrm{~m}$, the resulting thicknesses would be $z_{\mathrm{i}}=3.7 \mathrm{~m}$ and $z_{\mathrm{i}}=2.2 \mathrm{~m}$, respectively. Eq. (1) was applied for $d_{\mathrm{EM}}$ shown in Fig. 5a and all other bow measurements.

\subsubsection{Lateral resolution}

From Fig. 5a it can be seen that the laser is able to resolve the centimetre- to decimetre-scale roughness of the ice surface. In contrast, the electromagnetically derived distance to the ice underside is only slowly varying. The calculated ice thickness behaves as a superposition of both parameters (Fig. 5c). In particular, the EM signal responds with a time lag to the presence and absence of ice, and, as shown later, does not fully respond to pressure ridges. This behaviour is mainly a result of volume-averaging effects governing the EM measurements, and of the instrument's time constant of $1 \mathrm{~s}$. To get a better estimate of the potential lateral resolution of the EM measurements, spectral analysis of $d_{\mathrm{EM}}$ and $d_{\text {Laser }}$ as well as of derived ice thickness and freeboard was carried out. As mentioned above, the latter was calculated by removing the vertical ship motion from the laser data (Hibler, 1972).

Fig. 9 gives an example for power spectra and normalized ACFs of $d_{\mathrm{EM}}, d_{\text {Laser }}, z_{\mathrm{i}}$ and freeboard for a $15 \mathrm{~km}$ long section from the Amundsen Sea.
The difference between the low frequencies dominating in $d_{\mathrm{EM}}$ and high frequencies in $d_{\text {Laser }}$ is clearly seen. Since $z_{\mathrm{i}}$ was derived by subtracting $d_{\text {Laser }}$ from $d_{\mathrm{EM}}$, its spectrum approximates the spectra of $d_{\text {EM }}$ and $d_{\text {Laser }}$ at very low and high wavenumbers, respectively. The ACFs of $d_{\mathrm{EM}}$ and $d_{\text {Laser }}$ approach zero only gradually, corresponding to large correlation lengths. On average, for 10 to $25 \mathrm{~km}$ long profile sub-sections the correlation lengths were 56 \pm 47 and $38 \pm 12 \mathrm{~m}$ for $d_{\mathrm{EM}}$ and ice thickness and $9 \pm 2$ and $6 \pm 2 \mathrm{~m}$ for $d_{\text {Laser }}$ and freeboard, respectively. This clearly shows the loss in spatial variability in the EM data, provided that the true surface and underside roughnesses are similar.

In principle, draft can be derived by subtracting freeboard from ice thickness. However, due to application of the Hibler-method here freeboard represents the surface elevation above the flat ice surface serving as a reference level. The true freeboard will mostly be greater. Therefore the resulting draft and subsequently $R$ (the ratio of mean draft and freeboard) will be too big. Nevertheless, comparison of freeboard and draft PDFs may still be legitimate, as only the trends of their tails will be considered (Section 2.4).

An exemplary comparison of draft and freeboard PDFs of a $21 \mathrm{~km}$ long profile from the Bellingshausen Sea is shown in Fig. 10 (solid curves). Deep draft $>3 \mathrm{~m}$ is clearly underrepresented if compared
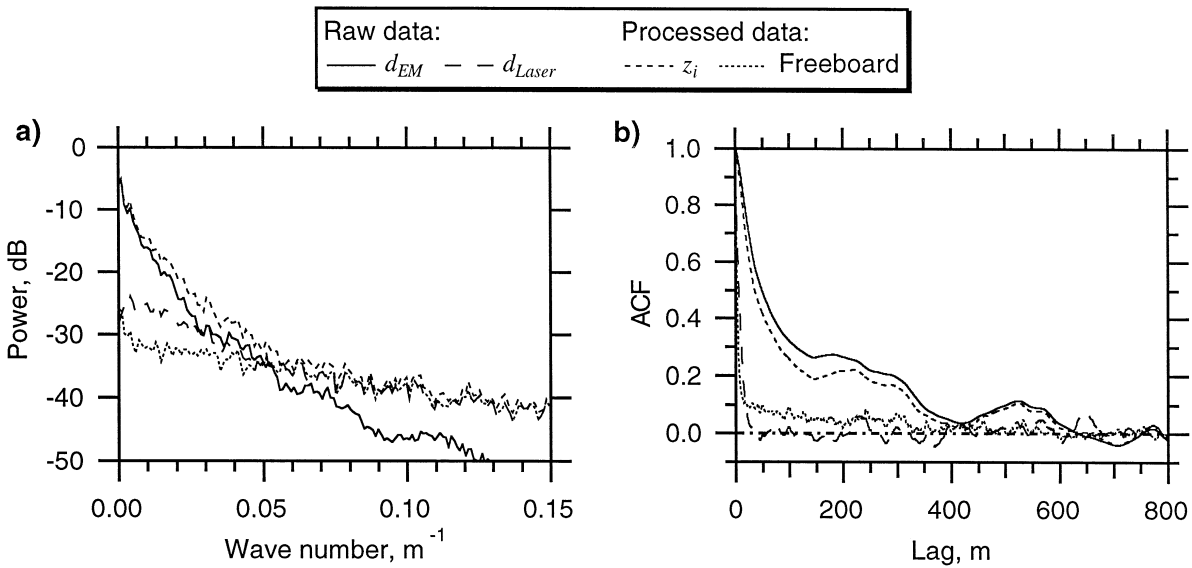

Fig. 9. Exemplary power spectra (a) and normalized ACFs (b) for EM signal $d_{\mathrm{EM}}$, laser distance $d_{\text {Laser }}$, ice thickness $z_{\mathrm{i}}$ and freeboard for a $15 \mathrm{~km}$ long section from the Amundsen Sea. 


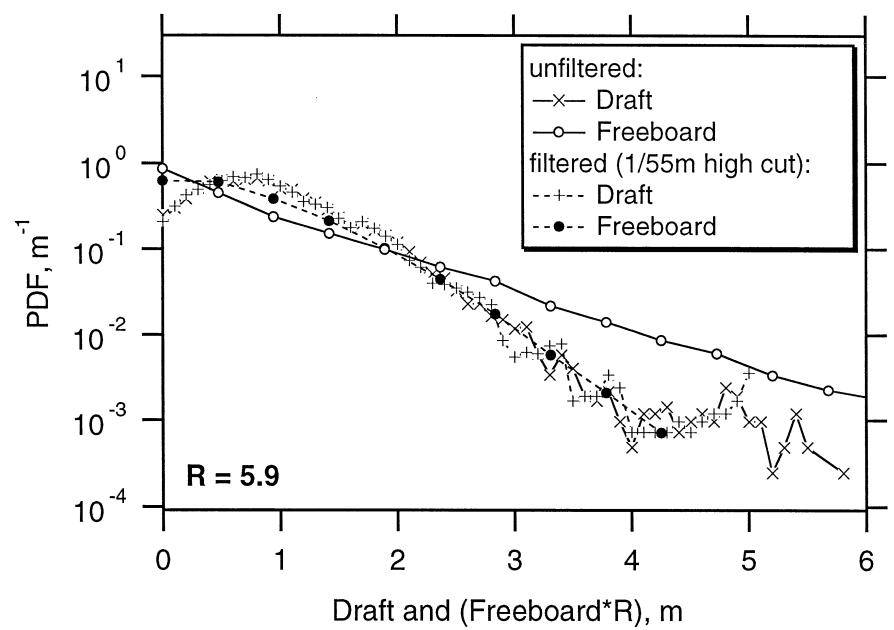

Fig. 10. Exemplary comparison of freeboard and draft PDFs of a $21 \mathrm{~km}$ long section from the Bellingshausen Sea. The freeboard PDF was transformed by means of $R$ (see text). The PDFs of low-pass filtered data are also shown.

to freeboard. As there deep draft and high freeboard measurements are mainly originating from pressure ridges, the comparison shows again that ice keel depths are not well determined by the system. In contrast, if the EM and laser data are low-pass filtered, above a critical frequency threshold good agreement between the PDFs can be achieved (Fig. 10). The dashed curves in Fig. 10 for example were calculated for a minimum wavelength of $55 \mathrm{~m}$. This is another indication for the limit of the achievable lateral resolution for pressure ridges.

\subsubsection{Accuracy of ice thickness estimates}

The slowly varying EM signal described above results in wrong thickness estimates particularly around floe edges (Fig. 5). Over the adjacent water the derived thicknesses are not zero, while over ice they have not reached an average value yet. Therefore for the following ice thickness calculations, water and a boundary zone of $10 \mathrm{~m}$ from the edges into the floes were excluded. This meant a considerable reduction in data as many floes were smaller than $20 \mathrm{~m}$ and thus were completely eliminated.

Fig. 11 presents composite thickness PDFs for the four profiles introduced in Fig. 1. The PDFs of 10 to $25 \mathrm{~km}$ long sub-sections are also shown (stippled lines). It can be seen that the data are very consistent and that the ice conditions along each profile did not vary much. The ice in the central Bellingshausen Sea had mean thicknesses of 1.3 to $1.4 \mathrm{~m}$ and a mode of the thickness PDFs at $0.9 \mathrm{~m}$ (Fig. 11a,b). In contrast, in the eastern Amundsen Sea the ice was much thicker with mean thicknesses from 2.3 to $3.1 \mathrm{~m}$. On profile 054 , two modes of 2.7 and $3.1 \mathrm{~m}$ were found (Fig. 11c). On profile 055, the mode was only $1.6 \mathrm{~m}$ (Fig. 11d). The thinner ice along profile 055 is believed to be a result of the closer vicinity to the ice edge. The width of the PDFs indicate a higher degree of variation in thickness due to deformation (see Appendix A). Mode, mean and standard deviation of ice thickness for each profile excluding open water and floe edges are shown in Table 1.

Fig. 12 summarizes all thickness measurements for the Bellingshausen (profiles 044 and 049) and the Amundsen Sea (profiles 054 and 055). At the top, the mean thicknesses from all drill holes along with their standard deviations (thick error bars) and minimum and maximum values (thin error bars) are given. The dashed curves in the lower part of Fig. 12 summarize the thickness PDFs from Fig. 11. The figure shows that drill-hole and bow measurements agree reasonably well and that the ice in the Amundsen Sea was significantly thicker.

The solid lines in Fig. 12 show the thickness PDFs for the complete data sets, i.e. data from both ice and water were used for their calculation. The additional modes at $0 \mathrm{~m}$ represent the open water fraction which was higher in the Bellingshausen Sea. 

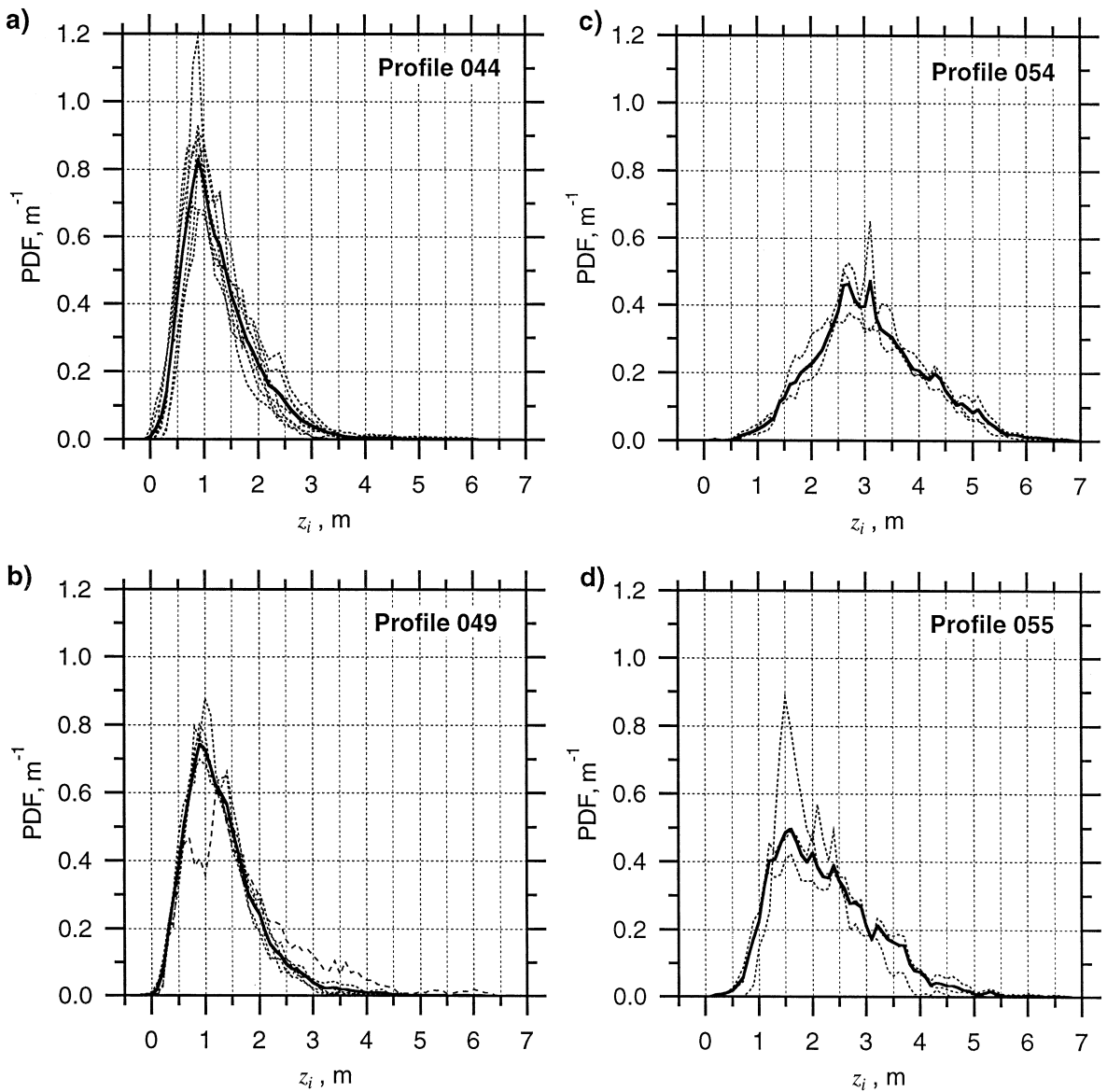

Fig. 11. Composite ice thickness PDFs for all profiles (see Fig. 1) measured with the ship (solid curves). The dashed curves were calculated for 10 to $25 \mathrm{~km}$ long sub-sections. All PDFs were derived by excluding water and floe edges from the data (see text).

However, as explained above, the sharp contrast between ice and water is highly blurred due to the slow response of the EM measurements.

Table 1

Results of the bow measurements

\begin{tabular}{lllllll}
\hline Profile & $\begin{array}{l}\text { Length } \\
(\mathrm{km})\end{array}$ & $\begin{array}{l}C_{\mathrm{i}} \\
(\%)\end{array}$ & $\begin{array}{l}\bar{\phi}_{i} \\
(\mathrm{~m})\end{array}$ & $\begin{array}{l}\bar{\phi}_{w} \\
(\mathrm{~m})\end{array}$ & $\begin{array}{l}\bar{z}_{\mathrm{i}} \\
(\mathrm{m})\end{array}$ & $\begin{array}{l}\text { Mode } \\
(\mathrm{m})\end{array}$ \\
\hline 044 & 130.1 & 61 & 24 & 16 & $1.30 \pm 0.66$ & 0.9 \\
049 & 124.1 & 70 & 44 & 20 & $1.35 \pm 0.70$ & 0.9 \\
054 & 37.8 & 84 & 27 & 5 & $3.12 \pm 1.04$ & $2.7 / 3.1$ \\
055 & 31.0 & 64 & 16 & 8 & $2.31 \pm 1.00$ & 1.6 \\
\hline
\end{tabular}

Ice concentration $C_{\mathrm{i}}$ and mean diameters of profiled floes $\bar{\phi}_{\mathrm{i}}$ and open water (cracks and leads) $\bar{\phi}_{w}$ were determined from the complete laser data set. Mean thicknesses $\bar{z}_{\mathrm{i}}$, standard deviations, and the modes of the distributions (cf. Fig. 11) were calculated excluding open water and a boundary zone of $10 \mathrm{~m}$ at floe edges (see text).
Table 1 also contains information about ice concentration $C_{\mathrm{i}}$ and mean floe and lead widths $\bar{\phi}_{\mathrm{i}}$ and $\bar{\phi}_{\mathrm{w}}$ which were determined from the distribution of ice and water in the laser data (including floe edges and small floes). From this table, the regional differences in ice concentration were not as high as might be deduced from the PDFs in Fig. 12. Mean floe diameters were higher in the Bellingshausen Sea, as were the mean widths of crossed leads. However, these values are highly biased by the fracturing of floes due to the ship. This will be further addressed in the discussion.

\subsubsection{Ridge statistics}

Pressure ridge statistics were independently derived from the laser data and calculated for a cut-off 

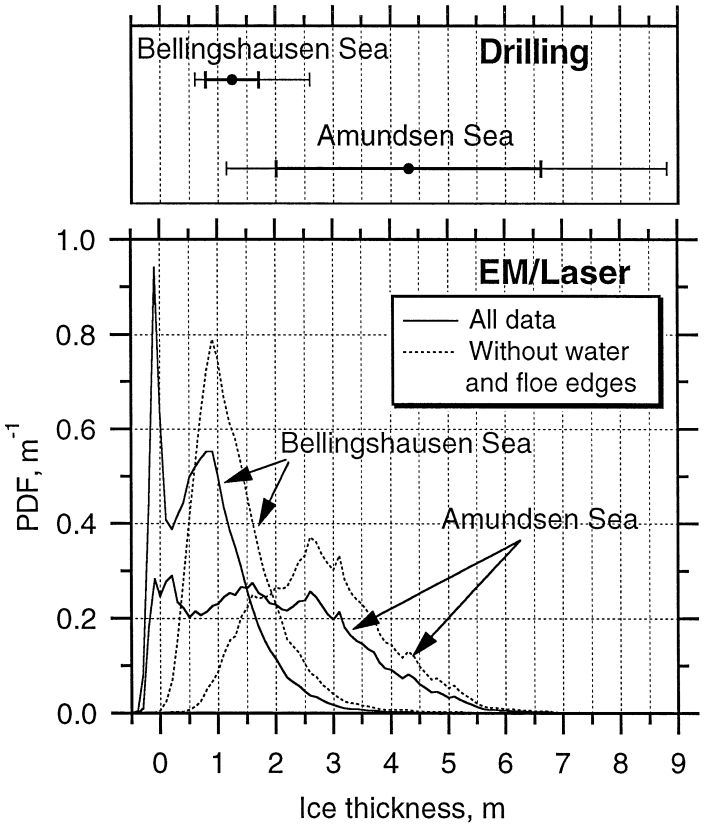

Fig. 12. Composite ice thickness PDFs for the Bellingshausen (profiles 044 and 049) and Amundsen Sea (profiles 054 and 055) as measured from the ship (bottom). Distribution including (solid) and excluding water and floe edges (stippled) are shown. The top graph shows mean drilling results (dots), their standard deviation (thick error bar) and minimum and maximum values (thin error bars).

height of $0.8 \mathrm{~m}$. The ice in the Bellingshausen Sea (profiles 044 and 049) was found to be moderately deformed with mean ridge heights of $1.06 \mathrm{~m}$ and spacings of $207 \mathrm{~m}$. If this is compared with mean floe diameters, it infers that many of the profiled floes had no ridges higher than $0.8 \mathrm{~m}$. In contrast, the ridges measured in the Amundsen Sea had a mean height of $1.17 \mathrm{~m}$ with mean spacings of $47 \mathrm{~m}$. Thus, the thick ice there was also much more deformed. The results we present here agree reasonably well with results from helicopter laser altimeter flights over the same regions (T. Viehoff, unpubl. data; see also Haas et al., 1996).

\section{Discussion}

A major problem of ship-based measurements of sea-ice thickness not addressed above is the influence of the ship itself on the ice. During ice-breaking cracks often form, extending from the bow straight ahead into the floe beneath the instrument. This has the effect of decreasing the apparent ice concentration and floe sizes. If cracks extend under the system, but not directly below the laser, they cannot be identified. However, the water filling these cracks increases the measured apparent conductivity and thus reduces the interpreted ice thickness. Therefore, suspension of the instruments further away from and slightly to one side of the ship would be optimum. In principle, fracturing, rafting and other influences of the ship on the ice will vary and depend on factors like ice thickness, floe size and ice concentration. Thus, the measurements in the Bellingshausen and Amundsen Sea were mainly hampered by the small floes which cracked easily and partially moved when the ship was ramming them. Therefore, values given in Table 1 for $C_{\mathrm{i}}, \bar{\phi}_{\mathrm{i}}$ and $\bar{\phi}_{\mathrm{w}}$ have to be taken with care. On the other hand, where floes were small but closely spaced, the ship could not avoid them and follow the leads around them, and therefore the profiles were quite linear.

Spectral analysis showed that the EM instrument was responding very slowly to changes in ice thickness. Low frequencies dominate the frequency spectra and autocorrelation lengths are as large as $60 \mathrm{~m}$. Therefore, single, narrow ice keels cannot be resolved and derived thicknesses are only mean values for whole floes. The thickness distributions presented in Figs. 11 and 12 represent functions of laterally, low-pass filtered thickness profiles, as could be shown with the direct comparison of freeboard and draft PDFs in Fig. 10.

The reasons for the poor lateral resolution are manyfold. The EM technique itself is inherently integrating laterally. However, according to Kovacs et al. (1995) this should only be in the order of $15 \mathrm{~m}$. The instrument's time constant of $1 \mathrm{~s}$ means that the instrument responds only fully to a change in ice thickness over a distance of $3 \mathrm{~m}$, if the ship speed was for example $3 \mathrm{~m} / \mathrm{s}$. Also with respect to the vertical resolution, the measurements approached the instrument's limitations. The penetration depth is relatively small and in measurements with the instrument located directly on the ice surface only thicknesses of up to about $6 \mathrm{~m}$ can be resolved with high accuracy (Kovacs and Morey, 1991; Haas et al., 1997). With an instrument height of $4 \mathrm{~m}$, the effec- 
tive accurately measurable ice thickness therefore reduces to only $2 \mathrm{~m}$. Thus, to ice thicker than $2 \mathrm{~m}$ the instrument responds only very little. This also decreases the prevalent lateral frequencies.

Finally, resolution is reduced due to the effect of the gap upon the transformation of apparent conductivity into $d_{\mathrm{EM}}$. As demonstrated by model calculations (Haas, 1997), gaps within the ice reduce the instrument's sensitivity to thickness changes below those gaps. This can be seen in Fig. 8b, where the gradient of the gap-model curve is smaller than that of the standard case with negligible ice conductivity. Thus, the ice properties in this study were unfavourable for EM measurements. For a more comprehensive evaluation the EM/laser system should be tested over less anomalous ice, e.g. in the Arctic.

Another consequence of the slow response time of the instrument is that derived thicknesses over small cracks between floes are not zero but have a finite value. Therefore, the PDFs for the complete data sets in Fig. 12 differ considerably in their representation of open water (ice thickness $0 \mathrm{~m}$ ), although from Table 1 the ice concentrations in the Bellingshausen and Amundsen seas were quite similar. This can be explained by the small lead widths in the Amundsen Sea. Here, the time needed to cross the narrow leads often is too short for the instrument to adjust to zero ice thicknesses.

\section{Conclusion}

A combined EM/laser system suspended below the bow crane of an icebreaker and consisting of relatively inexpensive commercially available instruments was tested for its potential to determine sea-ice thickness. The system was easy to handle with minimal logistical or technical effort. The same EM instrument can also be used directly on the ice for calibration or additional high-resolution measurements.

The measurement configuration generally combines the advantages of ground-based and airborne surveys, as extended profiles can be easily achieved and the distance to the ice or water surface is still small, thus principally enabling good vertical and lateral resolution. However, the particular system in use had a very poor lateral resolution. This was caused mainly by the limits of the EM instrument employed which was originally constructed for different tasks. With a different EM system with higher sensitivity and smaller coil spacing the lateral and vertical resolution could be significantly improved. Ideally, an instrument otherwise used in airborne surveys suspended below a helicopter could be used effectively from a ship.

Nevertheless, the used system is believed to yield reliable mean thicknesses, as was confirmed by the comparison with drill-hole measurements and visual observations. Thus, the system is appropriate to distinguish between different ice regimes or to observe seasonal and interannual thickness changes. Therefore, it can also yield valuable information for the validation of large-scale numerical sea-ice models.

The general importance of accompanying ground-based measurements for the calibration and validation of any EM study was shown. Here, they revealed unusually high ice conductivities, which then had to be considered for the instrument calibration. The derived ice properties may be typical for perennial Antarctic sea ice in summer, and can hamper EM measurements significantly. The derived thicknesses confirm earlier findings for the Amundsen Sea being one of the perennial sea-ice regions of the Antarctic having the thickest ice.

\section{Acknowledgements}

The measurements could not have been performed without the favourable ice conditions met, allowing reasonable progress without enabling the ship to follow leads to avoid the ice. The support of chief scientist Prof. H. Miller as well as of captain Allers and his crew of RV Polarstern is gratefully acknowledged. H. Martens and W. Cohrs helped much to technically realize the measurements. Thanks to D. Thomas and T. Viehoff for their great support and cooperation in the field. Finally, I am obliged to H. Eicken for any help and discussion. This is AWI Contribution No. 1307.

\section{Appendix A. Discussion of measured ice thick- nesses and properties}

Only a few ice thickness measurements from the Bellingshausen and Amundsen Sea have been reported to date. Jeffries et al. (1994) found level ice 
thicknesses of 1 to $4 \mathrm{~m}$ from a few ice cores in the region of the present study. During a winter expedition in 1993 to a region slightly further north, Worby et al. (1996) determined mean first-year ice and snow thicknesses of $0.9 \mathrm{~m}$ and $0.23 \mathrm{~m}$, respectively, by drilling. These observations are confirmed by the present data set (Table 1, Figs. 11 and 12). From the analysis of AVHRR satellite images which show distinct regions each with similar ice conditions (Haas and Viehoff, 1994) it is concluded that the derived thicknesses are also valid for a wider region around the profiles.

Nothing is known about ice drift pattern in the region. Therefore, the floes profiled in the Bellingshausen Sea in February 1994 may have belonged to the same ice fields which were measured by Worby et al. (1996) in the previous winter during AugustSeptember 1993. Nevertheless, the ice plus snow thicknesses from the present study are significantly higher (Figs. 1 and 11a,b, Fig. 12, Table 1). This may be a continuation of the trend of southward increasing thicknesses found by Worby et al. and of ongoing freezing until the onset of summer, but could also be the result of the ice being older than the first-year ice further north. Therefore, it is unlikely that a sea-ice retreat observed in this region by Jacobs and Comiso (1993) by means of analyses of SSM/I data from 1988 to 1991 has continued until 1992/1993. Since extensive freezing commenced at the end of February 1994 (Haas and Viehoff, 1994), the ice will also have survived another summer and will have aged further.

The measured and derived ice thicknesses in the Amundsen Sea are amongst the thickest ever reported for Antarctic sea ice (Wadhams et al., 1987; Lange and Eicken, 1991; Allison and Worby, 1994). These are likely to be the result of strong deformation rather than thermodynamic growth. This is underlined by the results of the laser profiles (Section 4.3.4). Ridge parameters derived for the Bellingshausen Sea are comparable with values found for winter first-year ice in the Weddell Sea (Lytle and Ackley, 1991; Dierking, 1995) and the Ross Sea (Weeks et al., 1989). In contrast, conditions in the Amundsen Sea were comparable with observations of Dierking (1995) in coastal zones of the Weddell Sea where highly deformed ice with characteristic shear zones was found.
The comparison of drill-hole measurements with electromagnetically determined apparent conductivity revealed significantly increased ice conductivities, which could not be neglected in the calculation of ice thickness. The increased conductivities could be explained by the seawater-filled gap within the upper portion of the ice. Although the data scatter much around the modelled $\sigma_{\mathrm{a}} / z_{\mathrm{i}}$ relation and the model is rather general (cf. Figs. 6 and 7), it is believed that by means of the EM measurements the representativeness of those gaps or high-porosity zones with lateral dimensions of metres for the whole region of perennial ice could be shown. On the one hand, the gap in the model accounts for high porosities throughout the ice due to the high ice temperatures close to $0^{\circ} \mathrm{C}$; on the other hand, it represents real gaps or zones of very high porosity. The occurrence of such gaps may be typical for perennial Antarctic ice in summer. It is believed to be a result of melt and freeze processes at the snow/ice interface associated with a very thick snow cover (Kawamura et al., 1993; Ackley and Sullivan, 1994; Jeffries et al., 1997). Therefore, such conditions are unlikely to be found in the Arctic where different seasons have little effect on EM measurements (Haas et al., 1997).

\section{References}

Ackley, S.F., Sullivan, C.W., 1994. Physical controls on the development and characteristics of Antarctic sea ice biological communities - a review and synthesis. Deep-Sea Res. I 41 (10), 1583-1604.

Allison, I., Worby, A.P., 1994. Seasonal changes of sea ice characteristics off East Antarctica. Ann. Glaciol. 20, 195-201.

Anderson, W.L., 1979. Computer Program. Numerical integration of related Hankel transforms of orders 0 and 1 by adaptive digital filtering. Geophysics 44, 1287-1305.

Coachman, L.K., Aagaard, K., 1974. Physical oceanography of Arctic and subarctic seas. In: Herman, Y. (Ed.), Marine Geology and Oceanography of the Arctic seas. Springer Verlag, Berlin, pp. 1-72.

Comiso, J.C., Wadhams, P., Krabill, W.B., Swift, R.N., Crawford, J.P., Tucker, W.B. III, 1991. Top/bottom multisensor remote sensing of Arctic sea ice. J. Geophys. Res. 96 (C2), 2693 2709.

Dierking, W., 1995. Laser profiling of the ice surface topography during the Winter Weddell Gyre Study 1992. J. Geophys. Res. 100 (C3), 4807-4820.

Haas, C., 1997. Sea-ice Thickness Measurements using Seismic 
and Electromagnetic-Inductive Techniques. PhD Thesis (in German with English Abstr.). Polar Res. Rep. 223.

Haas, C., Viehoff, T., 1994. Sea ice conditions in the Bellingshausen/Amundsen Sea: Shipboard observations and satellite imagery during ANT XI/3. Internal Rep. 51, Dep. Physics, AWI.

Haas, C., Rebhan, H., Thomas, D., Viehoff, T., 1996. Sea ice. In: Miller, H., Grobe, H. (Eds.), The Expedition ANTARKTISXI/3 of RV 'Polarstern' in 1994. Polar Res. Rep., 188, 29-43.

Haas, C., Gerland, S., Eicken, H., Miller, H., 1997. Comparison of sea-ice thickness measurements under summer and winter conditions in the Arctic using a small electromagnetic induction device. Geophysics 62, 749-757.

Hibler, W.D. III, 1972. Removal of aircraft altitude variation from laser profiles of the Arctic ice pack. J. Geophys. Res. 77 (36), 7190-7195.

Jacobs, S.S., Comiso, J.C., 1993. A recent sea-ice retreat west of the Antarctic Peninsula. Geophys. Res. Lett. 20 (12), 11711174 .

Jeffries, M.O., Shaw, R.A., Morris, K., Veazey, A.L., Krouse, H.R., 1994. Crystal structure, stable isotopes $\left(\delta^{18} \mathrm{O}\right)$, and development of sea ice in the Ross, Amundsen and Bellingshausen Seas Antarctica. J. Geophys. Res. 99, 985-995.

Jeffries, M.O., Worby, A.P., Morris, K., Weeks, W.F., 1997. Seasonal variations in the properties and structural composition of sea ice and snow cover in the Bellingshausen and Amundsen Seas Antarctica. J. Glaciol. 43 (143), 138-151.

Kawamura, T., Ohshima, K.I., Ushio, S., Takizawa, T., 1993. Sea-ice growth in Ongul Strait, Antarctica. Ann. Glaciol. 18, 97-101.

Kovacs, A., Holladay, J.S., 1990. Sea-ice thickness measurements using a small airborne electromagnetic sounding system. Geophysics 55, 1327-1337.

Kovacs, A., Morey, R.M., 1988. Electromagnetic measurements of a second year sea ice floe. In: Sackinger, W.M., Jeffries, M.O. (Eds.), Port and Ocean Engineering under Arctic Conditions (POAC 88), Vol. 1, pp. 121-136.

Kovacs, A., Morey, R.M., 1991. Sounding sea-ice thickness using a portable electromagnetic induction instrument. Geophysics 56, 1992-1998.

Kovacs, A., Valleau, N.C., Holladay, J.C., 1987. Airborne electromagnetic sounding of sea-ice thickness and subice bathymetry. Cold Regions Sci. Technol. 14, 289-311.

Kovacs, A., Holladay, J.S., Bergeron, C.J., 1995. The footprint/altitude ratio for helicopter electromagnetic sounding of sea-ice thickness: Comparison of theoretical and field estimates. Geophysics 60, 374-380.

Lange, M.A., Eicken, H., 1991. The sea ice thickness distribution in the northwestern Weddell Sea. J. Geophys. Res. 96 (C3), 4821-4837.
Liu, G., Becker, A., 1990. Two-dimensional mapping of sea-ice keels with airborne electromagnetics. Geophysics 55, 239-248.

Lytle, V.I., Ackley, S.F., 1991. Sea ice ridging in the eastern Weddell Sea. J. Geophys. Res. 96 (C10), 18411-18416.

Morey, R.M., Kovacs, A., Cox, G.F.N., 1984. Electromagnetic properties of sea ice. CRREL Monogr. 84-2.

Multala, J., Hautaniemi, H., Oksama, M., Leppäranta, M., Haapala, J., Herlevi, A., Riska, K., Lensu, M., 1995. Airborne electromagnetic surveying of Baltic Sea ice. Univ. of Helsinki, Dep. of Geophysics. Rep. Ser. Geophys. 31.

Prinsenberg, S.J., Holladay, J.S., 1993. Using air-borne electromagnetic ice thickness sensor to validate remotely sensed marginal ice zone properties. In: HSVA (Ed.), Port and Ocean Engineering under Arctic Conditions (POAC 93), Vol. 2, pp. 936-948.

Rothrock, D.A., 1986. Ice thickness distribution - measurement and theory. In: Untersteiner, N. (Ed.), The Geophysics of Sea Ice. NATO ASI Ser. B, Physics 146, pp. 551-575.

Thomas, D.N., Lara, R.J., Haas, C., Schnack-Schiel, S.B., Dieckmann, G.S., Kattner, G., Noethig, E.-M., Mizdalski, E., 1997. Biological soup within decaying summer sea ice in the Amundsen Sea, Antarctica. AGU, Antarctic Research Series, in press.

Wadhams, P., 1994. Sea ice thickness changes and their relation to climate. In: Johannessen, O.M., Muench, R.D., Overland, J.E. (Eds.), The Polar Oceans and their Role in Shaping the Global Environment. AGU, Geophys. Monogr. 85, 337-362.

Wadhams, P., Davy, T., 1986. On the spacing and draft distribution for pressure ridge keels. J. Geophys. Res. 91 (C9), 10697-10708.

Wadhams, P., Lange, M.A., Ackley, S.F., 1987. The ice thickness distribution across the Atlantic sector of the Antarctic Ocean in midwinter. J. Geophys. Res. 92 (C13), 14535-14552.

Wadhams, P., Tucker, W.B. III, Krabill, W.B., Swift, R.N., Comiso, J.C., Davis, N.R., 1992. Relationship between sea ice freeboard and draft in the Arctic Basin, and implications for ice thickness monitoring. J. Geophys. Res. 97 (C12), 20325 20334.

Ward, S.H., Hohmann, G.W., 1988. Electromagnetic theory for geophysical applications. In: Nabighian, M.N. (Ed.), Electromagnetic Methods in Applied Geophysics-Theory, Vol. 1. SEG Monograph, Vol. 3, pp. 131-313.

Weeks, W.F., Ackley, S.F., Govoni, J., 1989. Sea ice ridging in the Ross Sea, Antarctica, as compared with sites in the Arctic. J. Geophys. Res. 94 (C4), 4984-4988.

Worby, A.P., Jeffries, M.O., Weeks, W.F., Morris, K., Ja-a, R., 1996. The thickness distribution of sea ice and snow cover during late winter in the Bellingshausen and Amundsen Seas, Antarctica. J. Geophys. Res. 101 (C12), 28441-28455. 